\title{
Senning operation for correction of the transposition of the great arteries, results, long-term outcome and quality of life
}

\author{
Miguel Angel Maluf \\ Disciplina de Cirurgia Cardiovascular, Universidade Federal de São Paulo, São Paulo, Brazil \\ Email: miguelmaluf@gmail.com
}

Received 17 April 2012; revised 18 May 2012; accepted 5 June 2012

\begin{abstract}
Objective: Long-term results after the Senning operation for transposition of the great arteries are little known. Sinus node dysfunction and systemic ventricular dysfunction are crucial in patient survival. We evaluated the results, long term outcome and quality of life in a group of 39 patients. Methods: The study was a retrospective analysis, of $39(39 / 40=$ 97.5\%) surgical surviving patients, submitted to Senning operation, with a mean follow-up time of 14.7 +/- 3.1 years. Electrocardiogram, echocardiogram, and chest radiograph series were performed every 6 months. Thirty six patients of this series underwent Holter study and ergometric test, to evaluate the physical capacity. Three patients living overseas were excluded. Results: There was only one late death (1/39) (late mortality $=2.5 \%$ ): a 16 year-old patient had a no cardiac death. The actuarial survival was $95.0 \%$ (38/40) (simple or with little VSD, TGA). The probability of staying in sinus rhythm, in 39 surviving patients was $77.1 \%$ (30) or normal right ventricular function was $76.5 \%$ (29), 10 to 20 years after operation. The incidence of sinus node and right ventricular dysfunction increased gradually over time. No reoperations and pacemaker implantation, was performed. Functional class: $I=30(85.7 \%)$ cases and functional class II $=5(14.3 \%)$ cases. Conclusions: Patients with simple TGA submitted to Senning procedure in our experience, presented during late follow-up: 1-Low incidence of right ventricular dysfunction and active arrhythmias; 2-Low mortality and no sudden death recorded; 3-Good quality of life and 4-Satisfactory surgical results (free of reoperation or definitive pacemaker implantation).
\end{abstract}

Keywords: Congenital Heart Disease; Surgery; Treatment Outcome

\section{INTRODUCTION}

Survival functional status and quality of life of patients with transposition of the great arteries (TGA), after an atrial switch operation (Senning or Mustard procedure) are reported to be reasonably good after 2 decades of life [1-8]. However, in many cases, It's possible to detect the function of the systemic right ventricle deteriorates, severe tricuspid regurgitation develops or the patients suffer from arrhythmias.

Several strategies are proposed to handle those patients with failed right ventricle, such as: tricuspid valve repair, conversion to arterial switch, or heart transplantation. In most of the cases, these procedures are performed after the right ventricular function has already deteriorated, as a consequence of high operative mortality [9].

In the present study we focused on the analysis of the long-term results of atrial switch procedure (Senning operation), to identify risk factors for long-term outcome and quality of life, in a group of patients with simple TGA.

This study was approved by the ethics committee of the University Federal de São Paulo, for Lima's Master thesis presentation [10].

\section{METHODS}

\subsection{Patient Information}

From July 1990 to December 2000, 40 consecutive patients with TGA; all patients were classified into two basic indications:

1) Patients with TGA and ASD, older than 30 days old.

2) Anomaly of coronary arteries: intramural coronary course or common origin of coronary artery.

In 37 cases submitted to palliative atrial switch (Senning operation), had atrial septal defect (ASD) and 3 cases had ASD + small muscular ventricular septal defect (VSD). These patients were operated at: Disciplina de Cirurgia Cardiovascular-Universidade Federal de São 
Paulo (UNIFESP). Out of 39 (97.5\%) surviving patients, thirty six $(94.8 \%)$ cases were included in a retrospective follow-up study.

Three patients, living overseas were excluded from this study.

The patients age at the moment of surgical correction was 1 month to 11 months (mean 5.3 months); male 21 (52.4\%). The clinic diagnostic was confirmed by Doppler-echocardiogram: d-TGA with ASD, In 37 (92.5\%) cases, and ASD + small muscular VSD (size: 3 to $4 \mathrm{~mm}$ of diameter), in three $(7.5 \%)$ cases, were present. All patients were submitted to Rashkind procedure prior to surgery (Table 1).

\subsection{Operative Technique}

The surgical approach was performed by median sternotomy, employing hypothermic cardiopulmonary bypass (CPB), after vena cava and aortic cannulation; Anterograte cold blood cardioplegia was infused into the aortic route for myocardial protection, administrated every 20 minutes. During bypass assistance it was employed the conventional ultrafiltration (CUF) and after July 1996, it was associated to modified ultrafiltration (MUF), after the bypass was discontinued.

In all patients was employed the Subramanian's technique modification using left atrial appendix flap, for reconstruction of the new atrial septum, discarding the use of any prosthetic tissue (Figure 1).

In order to avoid tunnel stenosis, the Hegar dilator was used to measure the diameter of the vena cava ostium (Figure 2). No patient required a more extensive enlargement of the right (Figure 3) or left atrium and interrupted suture was used, around the superior and inferior vena cava to avoid external restriction (Figure 4).

Small muscular VSD was maintained open in three patients. The CPB was discontinued and the patient kept on inotropic drugs and temporary atrio-ventricular pacemaker stimulation (when necessary) in order to support the hemodynamic performance.

\subsection{Statistical Analysis}

The surviving patients curve and relevant events, during

Table 1. Preoperative characteristics of patients.

\begin{tabular}{lccc}
\hline Characteristics & Patients (\%) & Mean & Range \\
\hline Age (months) & - & 5.3 & $1-11$ \\
Male & $21(52.4)$ & - & - \\
TGA + ASD & $37(92.5)$ & - & - \\
TGA + ASD + VSD* & $03(7.5)$ & - & - \\
Rashkind procedure & $40(100)$ & - & - \\
\hline
\end{tabular}

TGA: Transposition of the great arteries; ASD: Atrial septal defect; VSD: Ventricular septal defect; *Small muscular ventricular septal defect.

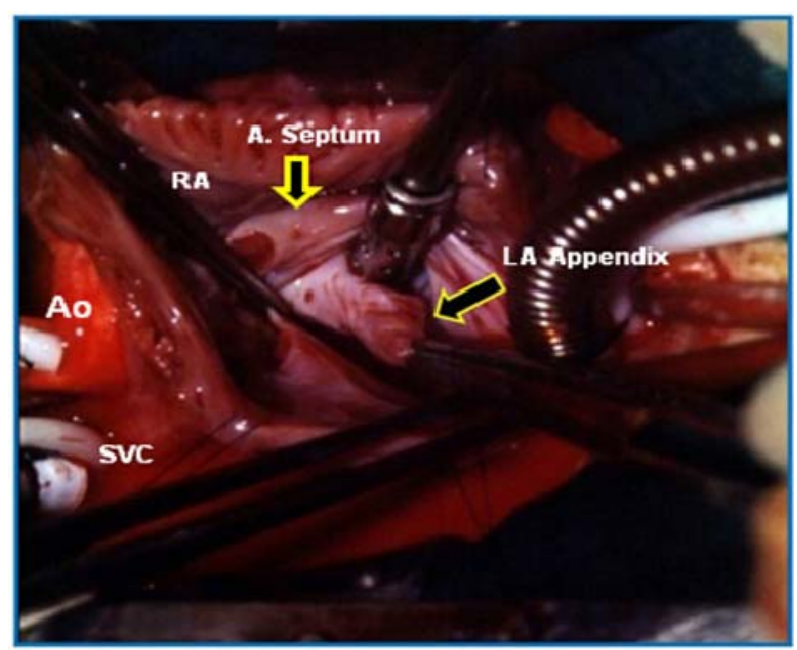

Figure 1. Operative photography. Right atriotomy exposure of the left atrial appendix (arrow) used for the closure of the atrial septal defect and construction of the roof of the left atrial tunnel. Ao: aorta; SVC: superior vena cava; RA: right atrium; A: atrial; LA: left atrial.

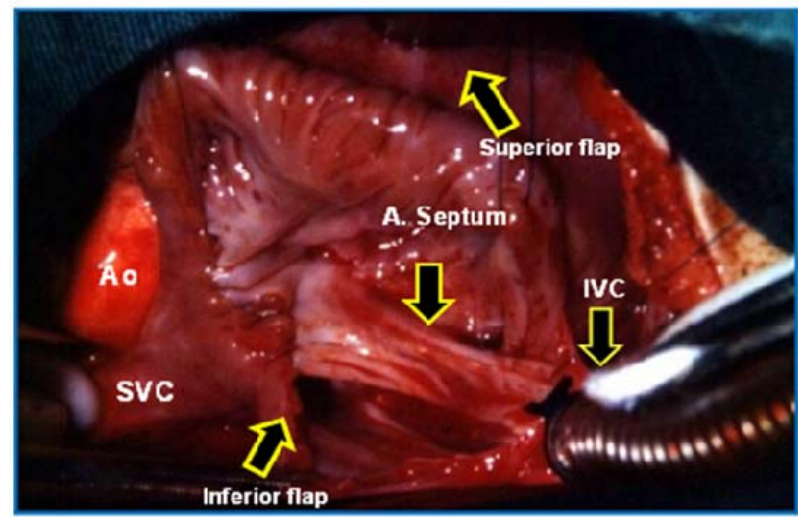

Figure 2. Operative photography. Right atriotomy exposure of the vena cava tunnel. The Hegar dilator (arrow), was employed to measure the inferior vena cava (IVC) ostium. Ao: aorta; SVC: superior vena cava; A: atrial.

the follow-up were performed according to the KaplanMeier's method, comparing 2 or more functions by the long-rank test. For all tests, a $p$ value of less than 0.05 was considered significant.

\section{RESULTS}

There was only one death $(1 / 39)$ (mortality $=2.5 \%)$, during the follow-up time (mean: $14.7+/-3.1$ years), a 16 year-old patient with bipolar disturbance committed suicide. The actuarial survival was $97.5 \%$ (simple TGA). The probability of staying in sinus rhythm, in 38 surviving patients was $71.1 \%$ (11 cases lost sinus rhythm). Eight $(21.0 \%)$ patients presented moderate dysfunction of RV, but three cases have mild RV dysfunction in the pre-operative period. 


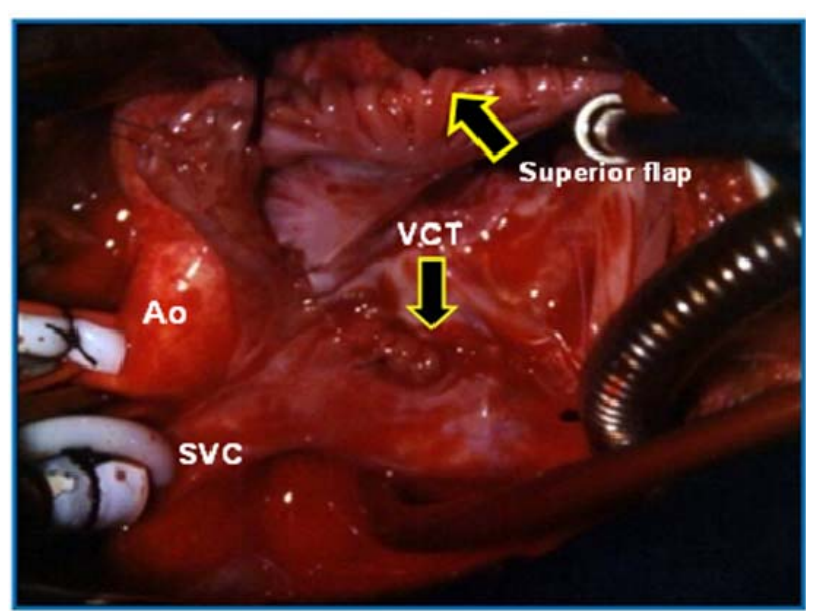

Figure 3. Operative photography. Right atriotomy exposure of the vena cava tunnel (VCT) finished. (arrow). Ao: aorta; SVC: superior vena cava.

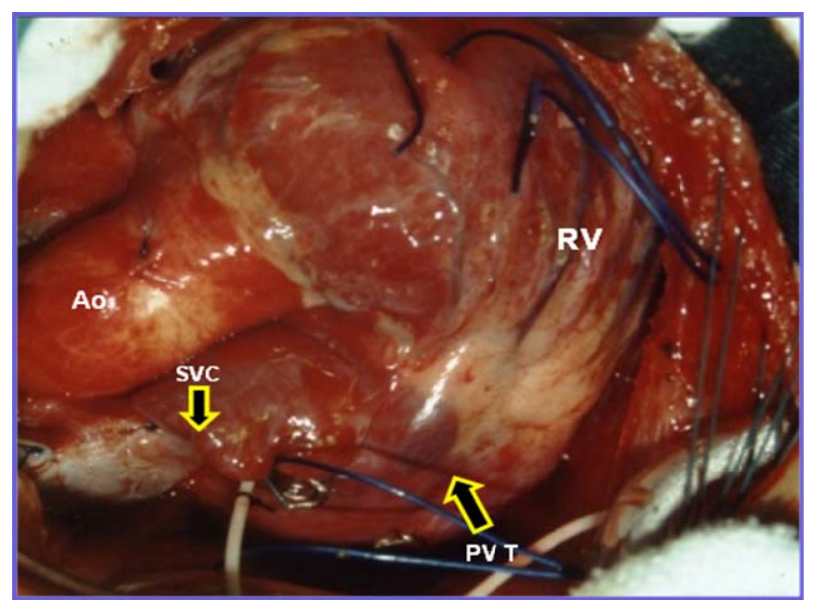

Figure 4. Operative photography. Surgery conclusion; we can observe the Interrupted suture over the superior vena cava (SVC) (arrow). PVT: pulmonary vein tunnel (arrow); Ao: aorta; RA: right atrium; RV: right ventricle.

Preserved RV function was observed in $30(78.9 \%)$ cases, 10 to 20 years after operation. The incidence for lost sinus rhythm and right ventricular dysfunction, increased gradually over time. Right ventricular dysfunction and active arrhythmias were not risk factors for late death.

All patients are free of reoperations and definitive pacemaker implantation (Table 2).

In our Institution, all patients were operated using the modified technique (Subramanian) and no estrange material was used.

Only two patients $(2 / 40=5.0 \%)$ presented stenosis of the IVC, during the early post-operative period; these patients were submitted to balloon angioplasty, with success. No re-operation was performed in this series of patients, during the late follow-up (mean 14.7 years).
Table 2. Operative procedure: Senning operation.

\begin{tabular}{ccc}
\hline \multirow{2}{*}{ Procedure } & \multicolumn{2}{c}{ Patients } \\
\cline { 2 - 3 } & $\mathrm{N}^{\circ}$ & $(\%)$ \\
\hline Senning operation & 40 & $(100)$ \\
$\begin{array}{c}\text { Small muscular VSD } \\
\text { (maintained open) } \\
\text { Moderated dysfunction of } \\
\text { RV }\end{array}$ & 03 & $(7.5)$ \\
\hline
\end{tabular}

VSD: Ventricular septal defect; RV: right ventricle.

\section{Late Follow-Up}

Thirty eight (95.0\%) surviving patients had mean followup of 177 months. Three patients were lost during the follow-up (living overseas).

Thirty five surviving patients $(87.5 \%)$ were submitted to Doppler - echocardiogram study (Figure 5) and Holter study, during 3 periods of follow-up: 0 to 60 months; 60 to 120 months and $>120$ months and the result of these exams were:

1) Tricuspid valve dysfunction: In 7 (20.0\%), 8 (22.8\%) and $10(28.5 \%)$ cases, respectively. Mild tricuspid insufficiency in $7(70.0 \%)$ cases and moderate insufficiency in $3(30.0 \%)$ cases.

2) Right ventricular dysfunction: In this study, we did not obtain right ventricular systolic and diastolic areas, owing to lack of Doppler-echocardiogram definition of the endocardial borders. The complex shape of the right ventricle limits the use of cross sectional echocardiography for assessing right ventricular function. The right ventricle is prone to considerable changes under abnormal preload and after load, which makes the right ventricular cavity even more geometrically complex. In addition, inadequate definition of the endocardium impedes accurate calculation of the area of the right ventricular cavity. The lower limit of normal for the RVEF, was considered $45 \%$. In $3(8.5 \%), 6(17.1 \%)$ and $8(22.8 \%)$ cases, in the respective period, the RVEF was below $45 \%$.

3) Cardiac arrhythmias: In 5 (14.2\%), 7 (20.0\%) and 8 $(22.8 \%)$ cases, of each respective period. Junction rhythm, in $5(62.5 \%)$ cases, Atrial fibrillation in $2(25.0 \%)$ cases and Atrial flutter in $1(12.5 \%)$ case.

4) Functional status: $28(80 \%)$ patients were in functional class I and $7(20 \%)$ cases, in functional class II (NYHA) (Table 3). The Kaplan-Meier survival curve (Figure 6) shows: late survival rate was $95.0 \%$ in the mean period of 14.7 years of follow-up. All patients are free of definitive pacemaker implantation and free of reoperation by right or left atrial tunnel stenosis repair, tricuspid valve plastic repair or right ventricle dysfunction.

\section{DISCUSION}

In the 1970 s and 1980 s, the atrial switch procedure was 

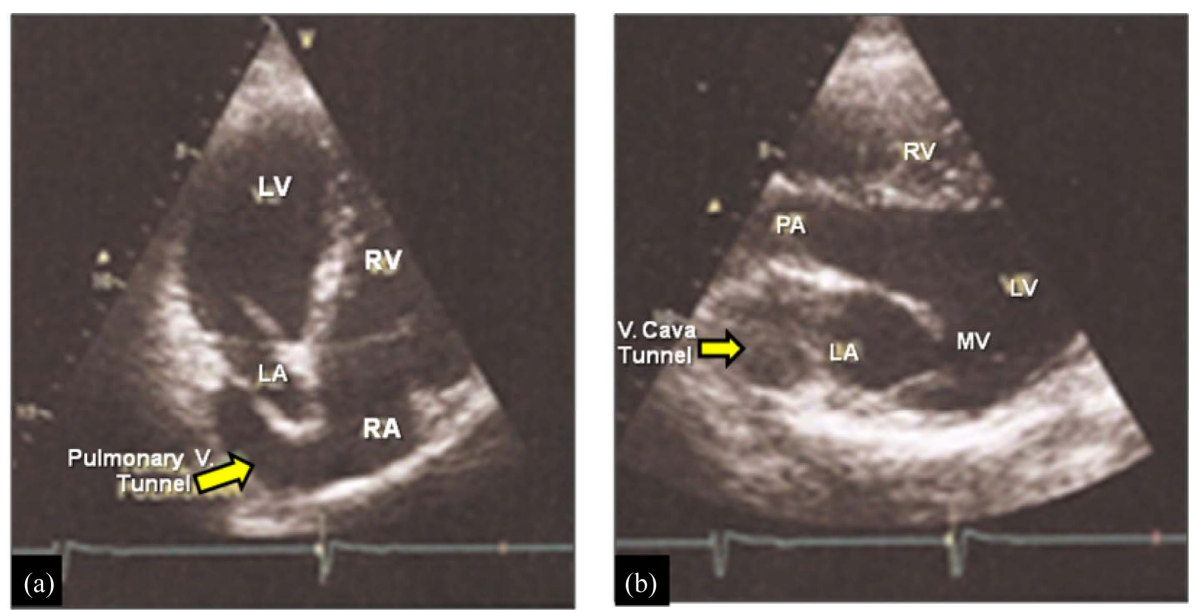

Figure 5. Post-operative Doppler-echocardiogram study. Patient: male, 16 years-old, in late follow-up of Senning operation. (a) Pulmonary vein tunnel draining into right atrium (arrow); (b) Vena cava tunnel draining into the left atrium. RA: right atrium; LA: left atrium; RV: right ventricle; LV: left ventricle; V: vena cava.

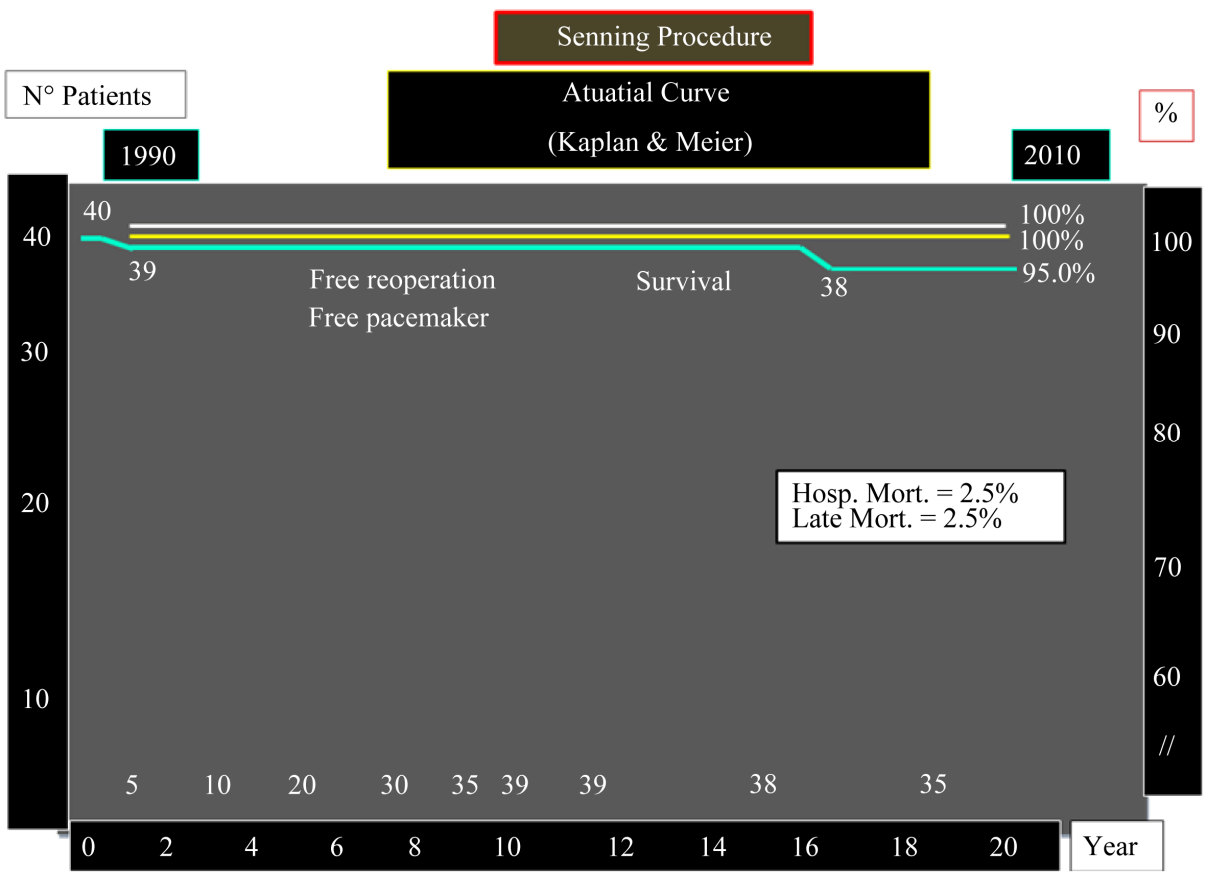

Figure 6. Actuarial kaplan \& meier curve. Late follow-up of patients submitted to Senning operation. Hosp. Mort.: hospital mortality.

Table 3. Late follow-up: patients with Senning operation (35 patients)*.

\begin{tabular}{ccccccc}
\hline $\begin{array}{c}\text { Time of Arrhythmias } \\
\text { Follow-up }\end{array}$ & \multicolumn{2}{c}{ Tricuspid V. Function } & \multicolumn{2}{c}{ RV function } & \multicolumn{2}{c}{ Cardiac } \\
\hline Normal & Insufficiency & Normal & Dysfunction & Sinusal R & Arrhythmias \\
\hline $0-60$ & $\mathrm{~N}^{\circ}(\%)$ & $\mathrm{N}^{\circ}(\%)$ & $\mathrm{N}^{\circ}(\%)$ & $\mathrm{N}^{\circ}(\%)$ & $\mathrm{N}^{\circ}(\%)$ & $\mathrm{N}^{\circ}(\%)$ \\
\hline $60-120$ & $28(80.0)$ & $7(20.0)$ & $32(91.4)$ & $3(8.6)$ & $30(85.7)$ & $5(14.3)$ \\
$>\quad 27(77.1)$ & $8(22.8)$ & $29(82.8)$ & $6(17.2)$ & $28(80.0)$ & $7(20.0)$ \\
\hline
\end{tabular}

*Patients operated $=40 ;$ Follow-up $=35$ patients (three patients were excluded); V: valve; RV: right ventricle; R: rhythm. 
the treatment of choice for patients with TGA. After Quaegebeur et al. reported favorable results with the Senning operation, in 1977, many groups with arterial switch results not satisfactory, started a new surgical experience with Senning's operation, in newborn patients.

In our Institution, from 1990 until the 2000's, the Senning's procedure was indicated for newborn and infant patients with TGA + ASD, using in all cases, the Subramanian's technique modification, with very satisfactory results.

\subsection{Baffle-Related Complications}

Baffle-related complications were the most frequent causes and accounted for $5.4 \%$ in the Senning group. The curves for freedom of baffle re-intervention, were only slightly different within the first 15 years but began to diverge clearly after that time span. The study published by the Congenital Heart Surgeons Society in 2000 [7] found the incidence of baffle-related complications in 173 Senning patients.

In a recent publication [11] the authors employed the inverted left atrial appendix, associated to autologous pericardium for venous pathway enlargement. This same group published, recently, the reoperation of one of these patients for retraction and calcification of the venous baffle, with obstruction of the venous tunnel.

In our Institution, the IVC stenosis during the early post-operative period, was resolved with success, employing balloon angioplasty.

\subsection{Right Ventricular Dysfunction}

Surgery for RV dysfunction is the second most frequent indication for reoperation. Mortality associated with reoperations in general has been described to be as high as $36 \%$ in a previously published series [9], mainly because of the high operative mortality of conversion to the arterial switch operation.

Three $(7.5 \%)$ patients in our series presented moderate RV dysfunction in the pre-operative period, but maintained the same RV dysfunction after Senning's operation, during the early and late follow-up, functional class II (NYHA).

\subsection{Cardiac Arrhythmias}

Loss of sinus rhythm at long term has been described in patients after atrial baffle procedures [7,8,12,13], with the incidence being the same after the Senning or the Mustard procedure [10]. However, Lange et al. [14] present in their series, sinus rhythm in $80.8 \%$ of the patients, 17.4 years after the Senning's procedure, which is higher than in other reported series $[13,14]$.

In these published articles, patients free from pacemaker implantation, in the Senning group, was $98.7 \%$, at
10 years and, thus, it was comparable to the findings by Turina et al. [15] (92\% at 10 years) and Wells and Blackstone [8] (91\% at 10 years) and freedom from pacemaker insertion was still $>90 \%$ at 20 years. This low incidence of cardiac arrhythmias, might be related to the fact that in these patients the coronary sinus was not incised as originally described by Senning and the atrial suture line was placed posterior to the coronary sinus [16].

To reduce the incidence of cardiac arrhythmias (5 cases $=14.3 \%$ ), the surgical technique employed to perform the Senning's operation included:

1) ASD closure using the inverted left atrial appendix.

2) The atrial suture line was placed posterior to the coronary sinus.

Thirty five (92.1\%) surviving patients had mean follow-up of 177 months (3 cases living overseas). During late follow-up, other 3 patients presented cardiac arrhythmias. Actually, $27(77.1 \%)$ cases maintain the sinus rhythm and $8(22.9 \%)$ cases presented cardiac arrhythmias. No pacemaker was implanted in this group of patients.

\subsection{Late Follow-Up}

Lange et al. [12] had $90.9 \% \pm 2.3 \%$ of surviving patients in 25 years of follow-up, after the Senning procedure and $75.9 \% \pm 4.8 \%$, after the Mustard procedure and thus, it was significantly different in invariable analysis. The Mustard procedure remained a significant risk factor for late death in multivariate analysis fully adjusted for all variables that were statistically significant between the 2 groups. This difference in late survival between the 2 operative procedures is not confirmed in all investigations.

Whereas, Sarkar et al. [14] observed a significantly better survival of patients after the Senning's operation (94\% versus $77 \%$ at 15 years), Wells and Blackstone [8] reported the Senning's operation to be a risk factor for late death. In contrast, Oechslin and Jenni [7] reported a similar long-term outcome for the Toronto Mustard group and the Zurich.

Senning group, with $\approx 75 \%$ survival after 25 years. However, they found a difference in the mode of death between the Mustard group and the Senning group. Similar to the results of the present study, relatively more Mustard patients died of sudden death compared with the Senning patients, who died preferentially of progressive congestive heart failure.

In 40 consecutive operations, we had one death (hospital mortality $=2.5 \%$ ); these results are possible to compare to others reported series, with mortality ranging from $2 \%$ to $5.4 \%[7,8,12,17]$. Whereas, patients with simple TGA submitted to Senning's operation, resulted in a significant difference in the relative number of complex TGA. In addition, the surgical learning curve may 
have been a reason for the differences in mortality between the different published reports in international issue.

We had a previous published report [10], including only the first 17 patients, submitted to Senning's operation, for correction of the simple TGA, in our Institution. In this series we have one hospital death, (early mortality $2.5 \%$ ).

Actually, there are thirty nine surviving patients with only one noncardiac death. The actuarial survival rate in our Institution is $95 \%$, with mean follow-up of $14.7 \%$ years.

Regarding the type of atrial baffle procedure, patients with previous VSD carry a higher risk of late death than patients with intact ventricular septum $[2,8,16]$. Kirjavainen et al. [3] show: $90 \%$ of the patients with simple TGA but only $78 \%$ of the patients with complex TGA, were alive 15 years after the Senning procedure. These data confirm the finding that the presence of a VSD is a significant risk factor for late death because VSD closure emerged as an independent risk factor for late death in multivariate analysis.

\subsection{Other Surgical Procedure}

From 1986, in our Institution, neonates with simple TGA, newborn with TGA plus VSD or Taussig Bing anomaly were referred to arterial switch operation (ASO) and VSD closure, but newborn patients with diagnosis of simple TGA and simple TGA with small muscular VSD were referred to Senning's operation.

The question remains of whether the surgical procedure of VSD closure or rather the hemodynamic consequences of a previous VSD account for the intrinsic risk of late mortality. Potential complications of VSD closure that may also lead to late RV dysfunction and consecutively to late death $[3,4]$, such as iatrogenic postoperative $\mathrm{AV}$ block or tricuspid valve insufficiency were no more frequent in patients after VSD closure.

However, freedom from pacemaker implantation was lower in patients who received VSD closure at the time of the atrial switch operation. The incidence of right bundle branch block (RBBB), which has been associated with late development of RV dysfunction, was increased. Hence, the surgical procedure of VSD closure may have an influence on mortality in the long term.

Deterioration of the function of the systemic ventricle (RV) is a major concern in patients after atrial switch procedures. The incidence of moderate or severe RV dysfunction shows a wide variation in the literature from $8 \%$ at 12 to 18 years and $20 \%$ at 20 to 28 years [4,9], respectively. Kirjavainen et al. [3] found a rapid increase of RV dysfunction, after 10 years, and described the probability of normal right ventricular function to be only $52 \%$ and $39 \%, 10$ to 15 years after the Senning's procedure in pa- tients with simple and complex TGA, respectively. In the Lange et al. [12] study, the incidence of RV dysfunction was $16.1 \%$ at 25 years. However. In our experience with 40 consecutive cases of Senning's operation, three patients presented mild RV dysfunction, before operation and maintaining after 15 years of follow- up, in functional class II. The RV variability in assessing right ventricular function and the lack of a uniform definition restrict comparison. The incidence of RV dysfunction in the long term has been shown to be associated with the complexity of the heart defect, [2-4,17], which we confirmed by Lange et al. [12] that this dysfunction progressed to moderate dysfunction, but maintaining the functional class II.

In our series, actually, 8 (22.8\%) patients presented mild or moderate RV dysfunction and tricuspid insufficiency; these patients are medicated with $\beta$ blocking drugs and patients with tachyarrhythmias are using antiarrhythmic drugs.

\section{CONCLUSION}

Our results confirm that the patients with simple TGA submitted to the Senning's procedure, presented in the late follow-up, good quality of life (functional class I-II), satisfactory results (low incidence of arrhythmias, free of pacemaker implantation or reoperation) and no risk of late sudden cardiac death.

\section{REFERENCES}

[1] Birnie, D., Tometzki, A., Curzio, J., Houston, A., Hood, S., Swan, L., Doig, W., Wilson, N., Jamieson, M., Pollock, J. and Hillis, W.S. (1998) Outcomes of transposition of the great arteries in the era of atrial inflow correction. Heart, 80, 170-173.

[2] Moons, P., Gewillig, M., Sluysmans, T., Verhaaren, H., Viart, P., Massin, M., Suys, B., Budts, W., Pasquet, A., De Wolf, D. and Vliers, A. (2004) Long term outcome up to 30 years after the Mustard or Senning operation: A nationwide multicentre study in Belgium. Heart, 90, 307313. doi: $10.1136 /$ hrt.2002.007138

[3] Kirjavainen, M., Happonen, J.M. and Louhimo, I. (1999) Late results of Senning operation. Journal of Thoracic and Cardiovascular Surgery, 117, 488-495. doi:10.1016/S0022-5223(99)70329-6

[4] Agnetti, A., Carano, N., Cavalli, C., Tchana, B., Bini, M., Squarcia, U. and Frigiola, A. (2004) Long-term outcome after Senning operation for transposition of the great arteries. Clinical Cardiology, 27, 611-614. doi:10.1002/clc.4960271107

[5] Gelatt, M., Hamilton, R.M., McCrindle, B.W., Connelly, M., Davis, A., Harris, L., Gow, R.M., Williams, W.G., Trusler, G.A. and Freedom, R.M. (1997) Arrhythmia and mortality after the Mustard procedure: A 30-year single-center experience. Journal of the American College of Cardiology, 29, 194-201. 


\section{doi:10.1016/S0735-1097(96)00424-X}

[6] Oechslin, E. and Jenni, R. (2000) 40 years after the first atrial switch procedure in patients with transposition of the great arteries: Long-term results in Toronto and $\mathrm{Zu}-$ rich. Thoracic and Cardiovascular Surgeon, 48, 233-237. doi:10.1055/s-2000-6901

[7] Williams, W.G., Mc Crindle, B.W., Ashburn, D.A., Jonas, R.A., Mavroudis, C. and Blackstone, E.H. (2003) Outcomes of 829 neonates with complete transposition of the great arteries 12-17 years after repair. European Journal Cardio-Thoracic Surgery, 24, 1-9. doi:10.1016/S1010-7940(03)00264-1

[8] Wells, W.J. and Blackstone, E. (2000) Intermediate outcome after Mustard and Senning procedures: A study by the Congenital Heart Surgeons Society. Seminars in Thoracic and Cardiovascular Surgery: Pediatric Cardiac Surgery Annual, 3, 186-197.

[9] Cochrane, A.D., Karl, T.R. and Mee, R.B. (1993) Staged conversion to arterial switch for late failure of the systemic right ventricle. Annals of Thoracic Surgery, 56, 854-861. doi:10.1016/0003-4975(93)90343-G

[10] Lima, L.C. (2001) Resultados tardios da correção da transposição das grandes artérias com comunicação interatrial com a técnica de Senning. UNIFESP, Tese Mestrado,

[11] Canêo, L., Lourenço, D., Silva, R., Franchi, S., Afiune, J., Afiune, C., Mocelin, A., Barbero-Marcial, M. and Jatene, F. (1999) Senning operation with autologous tissue for atrial septum augmentation or pulmonary venous pathway enlargement. Revista Brasileira de Cirurgia Cardiovascular, 14, 298-302

[12] Lange, R., Hörer, J., Kostolny, M., Cleuziou, J., Vogt, M.,
Busch, R., Holper, K., Meisner, H., Hess, J. and Schreiber, C. (2006) Presence of a ventricular septal defect and the mustard operation are risk factors for late mortality after the atrial switch operation. Circulation, 114, 1905-1913. doi:10.1161/CIRCULATIONAHA.105.606046

[13] Bender, H.W. Jr., Stewart, J.R., Merrill, W.H., Hammon, J.W. Jr. and Graham, T.P. Jr. (1989) Ten years' experience with the Senning operation for transposition of the great arteries: Physiological results and late follow-up. Annals of Thoracic Surgery, 47, 218-223. doi:10.1016/0003-4975(89)90272-5

[14] Sarkar, D., Bull, C., Yates, R., Wright, D., Cullen, S., Gewillig, M., Clayton, R., Tunstill, A. and Deanfield, J. (1999) Comparison of long-term outcomes of atrial repair of simple transposition with implications for a late arterial switch strategy. Circulation, 100, II-176-II-181. doi:10.1161/01.CIR.100.suppl 2.II-176

[15] Turina, M., Siebenmann, R., Nussbaumer, P. and Senning, A. (1988) Long-term outlook after atrial correction of transposition of great arteries. Journal of Thoracic and Cardiovascular Surgery, 95, 828-835

[16] Helbing, W.A., Hansen, B., Ottenkamp, J., Rohmer, J., Chin, J.G., Brom, A.G. and Quaegebeur, J.M. (1994) Long-term results of atrial correction for transposition of the great arteries: Comparison of Mustard and Senning operations. Journal of Thoracic and Cardiovascular Surgery, 108, 363-372.

[17] Reich, O., Voriskova, M., Ruth, C., Krejcir, M., Marek, J., Skovranek, J., Hucin, B. and Samanek, M. (1997) Longterm ventricular performance after intra-atrial correction of transposition: Left ventricular filling is the major limitation. Heart, 78, 376-381. 